\title{
Investigating Water Hammer Problem in Piped Water Distribution System
}

\author{
Joyanta Kumar Roy ${ }^{1} \&$ Pijush Basak ${ }^{2}$ \\ ${ }^{1}$ (Dept. of ECE, MCKV Institute of Engineering, WBUT, India) \\ ${ }^{2}$ (Dept. of Math, Narula Institute of Technology, WBUT, India)
}

\begin{abstract}
The water hammer in the form of disastrous surge pressure developed inside the piped water distribution system causes major damage. The one dimensional propagation of water surge pressure in a series of water pipes with varying diameter and angle has been studied theoretically. The numerical solution with different pipe materials for the pressure surge has also being evaluated. The sensible pressure due to surge varies significantly with pipe material and diameter but not much significantly with length and bending angle in a distribution layout.
\end{abstract}

Keywords: Joukwasky equation, Matlab Simulation, Piped water supply scheme, Surge pressure, Water hammer, Water supply protection

\section{INTRODUCTION}

The water is synonyms of life; a human being needs good amount of potable water for drinking, washing, cleaning and sanitation. The ground and catchment water are common source of drinking water and piped water supply is the common mode of distribution of water in mass populated area. The piped water supply scheme (Fig.1) normally consist of Raw water mains, Raw water pump house, Treatment plant, Clear water storage, Clear water pump house, Clear water mains, distribution mains, overhead reservoirs and consumer distribution pipelines having various components like valves, Traps etc.

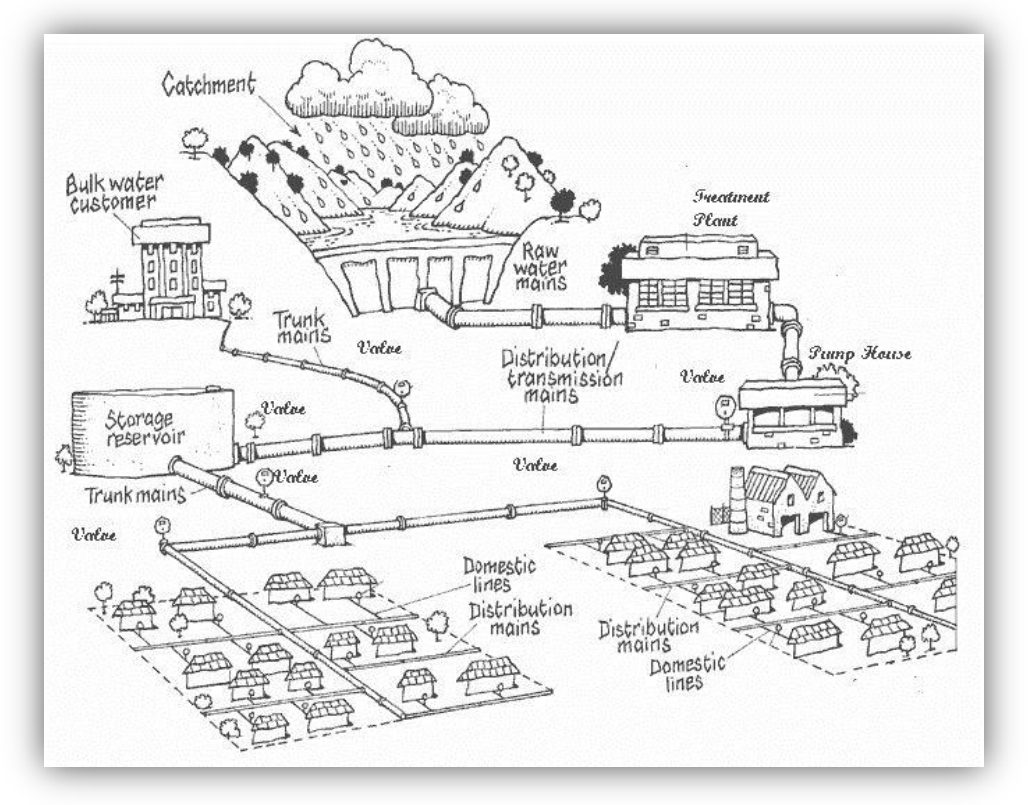

Fig.1: Typical water distribution system

It is desirable to have fault free water distribution system such that stakeholder gets water as per scheduled requirement without interruption. The resource department also deserves minimum down time for fault repairing or maintenance. Most of the piping systems in urban area are running through underground. Therefore any fault will be associated with time consuming excavation and repair works. However the underground pipe leakage and damage are the common issues in water supply system. In this contest we have studied the phenomenon of pipe damage due to massive impulsive force generated in the distribution called water hammer. 


\section{UNDERSTANDING THE WATER HAMMER}

In a pipe system of water mains, water flows with certain velocity steadily in the mains and branch pipes. However, for an instant closure of a valve, enormous pressure develops in the pipe system. The magnitude of the pressure under a transient condition is expressed by Joukowsky's equation of instant valve closure. [Arries \& Anderson, Ghidaoui et. al. 2005]

$$
\Delta p(\max )= \pm \rho \mathrm{c} \Delta \mathrm{v} / \mathrm{g}
$$

Where $\quad \Delta p(\max )=$ change in pressure in $\mathrm{kg} / \mathrm{m}^{2}, \quad \Delta v=$ change in average velocity in $\mathrm{m} / \mathrm{s}$

$\mathrm{r}=$ density of water in $\mathrm{kg} / \mathrm{m}^{3}, \quad \mathrm{~g}=$ acceleration due to gravity in $\mathrm{m} / \mathrm{s}^{2}$

$c=$ celerity or the speed of the surge wave through the liquid in the pipeline in $\mathrm{m} / \mathrm{s}$.

For cylindrical pipe of uniform cross section under consideration $\mathrm{c}$ is defined as

$\mathrm{c}=\sqrt{K 1} / \rho$ and $\mathrm{K} 1=\mathrm{K} /[1+(\mathrm{DK}) /(\mathrm{eE})]$

where $\mathrm{D}, \mathrm{e}, \mathrm{E}$ and $\mathrm{K}$ stands for diameter of the pipe, thickness of wall, modulus of elasticity of the material of pipe and bulk modulus of contained water. All the units mentioned in the above formula are in SI unit.

During a transient condition, the equation (1) indicates the huge amount of pressure (surge pressure) originated due to sudden closure of a valve. However, the surge pressure generated counts on several factors mainly the celerity of the pipe material. The assumptions in the development of the water hammer equations are [18]:

(1) Flow in the pipeline is considered to be one-dimensional with the velocity averaged and the pressure uniform at a section.

(2) Unsteady friction losses are approximated as quasi-steady state losses.

(3) The pipe is full and remains full during the transient.

(4) There is no column separation during the transient event, i.e. the pressure is greater than the liquid vapor pressure.

(5) Free gas content of the liquid is small such that the wave speed can be regarded as a constant.

(6) The pipe wall and the liquid behave linearly elastically.

(7) Structure-induced pressure changes are small compared to the water hammer pressure wave in the liquid.

Unsteady friction, cavitations and fluid structure interaction consideration are important, these parameters effects significant change in wave shape and propagation time of water hammer.

\section{WATER HAMMER IN WATER DISTRIBUTION SYSTEM}

Potable water is distributed from overhead reservoirs to the consumers through water pump and piped network. Overhead reservoirs are connected through branch lines whereas branch lines are connected with main pipe line named water mains. In a water supply system, vast area is covered with number of overhead reservoirs and those reservoirs requires systematic flow operation through pipes for availing of uniform pressure profile to the entire distribution area in a coordinated manner. In water supply distribution system, distribution mains normally has larger diameter. As the water travels through the pipe and distributed to the branch lines pressure reduces and therefore to maintain working pressure pipe diameters are reduced progressively with distance. There may be several bends and entire water supply network is very complicated depends on the water supply distribution pattern. Water hammer surge may develop due to non-synchronized operation of distribution valves.

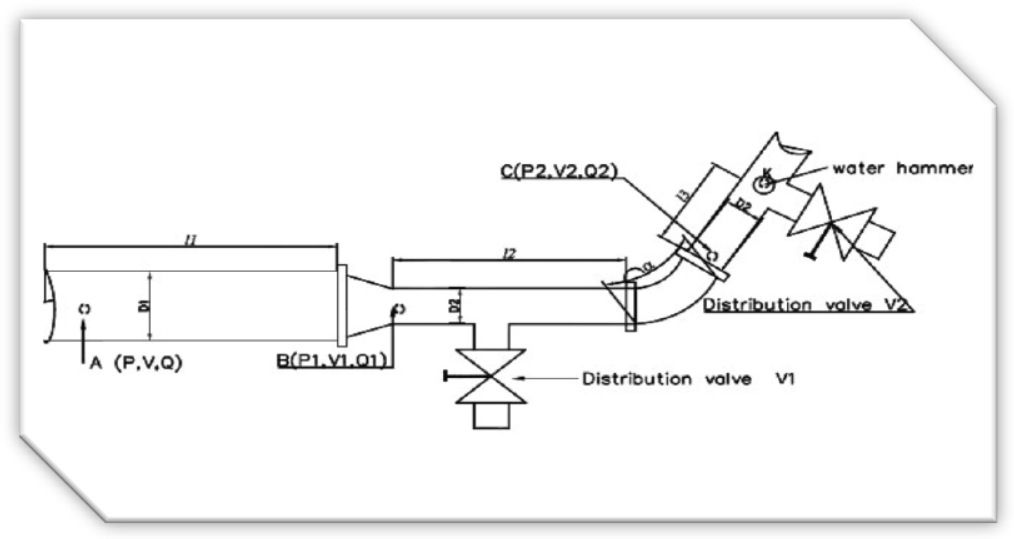

Fig.2: Typical piped water distribution system for Modeling 
To study water hammer model, we have consider a portion of the distribution pipes of different lengths and having two different diameters with a bend (Fig.2). A straight pipe of diameter $\mathrm{D}_{1}$ is connected to the pump supplying water to the overhead reservoir through valve V1 and another overhead reservoir through valve V2 travelling through the pipes of different lengths and diameters. Firstly, the pipe of length $1_{1}$ with diameterD $\mathrm{D}_{1}$ considered ( $\mathrm{AB}$ portion). Thereafter, the mass of water flows through a pipe of length $\mathrm{l}_{2}$ having diameter $\mathrm{D}_{2}(\mathrm{BC}$ portion). Finally, in line with the practical situation, a bend in the pipe of angle a is included and considered at C. The water mass now flows through a pipe of diameter $\mathrm{D}_{2}(\mathrm{C} C$ portion). The branch pipe connecting the reservoir through valveV2 is joined in this portion. The water mass however reaches (C) before closure of the valve V2. If valve V2 is instantly closed then consequently Water Hammer occurs at V2 at a distance $1_{3}$ from the point C. The average velocity at A inside the pipe is given by (Bansal 2000, Jain 1996)

$$
V=\frac{4 Q_{1}}{\pi D_{1}^{2}}
$$

Considering decay in pressure following transmission from A to B, the resultant pressure at B is (Garg, 2004: Jain, 1996)

$\mathrm{P}_{1}=\mathrm{P}-\frac{32 \mu \mathrm{Vl}_{1}}{\mathrm{D}_{1}^{2}}$

Where, $\mathrm{V}$ is velocity at $\mathrm{A}$. In the same way, due to transmission from $\mathrm{B}$ to $\mathrm{C}$, the resultant pressure at $\mathrm{C}$ is

$P_{2}=P_{1}-\frac{32 \mu \mathrm{V}_{1} \mathrm{l}_{2}}{\mathrm{D}_{2}^{2}}$

Where, $\mathrm{V}_{1}$ is average velocity at $\mathrm{B}$. At the point $\mathrm{C}$, the pipe bends at an angle a. Consequently, the amount of pressure dropped due to bending is (Idelchik1986, Rowe1970)

$\Delta P=\frac{f_{S} \rho V_{1}^{2} \pi R_{b}}{2 D_{2}} \cdot \frac{\theta}{180^{\circ}}+\frac{1}{2} K_{b} \rho V_{1}^{2}$

Here, $f_{s}, \mathrm{~V}_{1}, \mathrm{R}_{\mathrm{b}}, \theta$ are Moody's friction factor, mean flow rate, Bend radius and Bend angle at $\mathrm{C}$ respectively. After bending, the revised pressure at $\mathrm{C}$ subject to transmission is

$\mathrm{P}^{\prime \prime}=\mathrm{P}_{2} \quad-\Delta P$

Water flows the distance of $1_{3}$ from $\mathrm{C}$ to reach the valve at $\odot$ for reservoir through valve V2. The valve V2 is however, rapidly closed causing Water Hammer to occur. The resultant pressure there reduces to

$\mathrm{P}^{\prime \prime}=\mathrm{P} "-\left(32 \mu \mathrm{V}_{2} l_{3}\right) /\left(D_{2}{ }^{2}\right)+\mathrm{D} p(\max )$

Where, the second term is the decay of pressure for water mass to travel from $\mathrm{C}$ to $(\mathrm{C}$. The Third term is the Surge pressure generated at $\left(C\right.$ as indicated in the Section 1 (eqn. (1)). $V_{2}$ is the average velocity at $C$ defined by $V_{2}=\frac{4 Q_{2}}{\pi D_{2}^{2}}$

The revised pressure at $\mathrm{K}$ is subjected to transmission in both upstream and downstream. The downstream pressure after some dissipation would be sensed at A; this is certainly an application of Pascal's law.

Following decay of the water hammer pressure, the measurement of Sensed pressure that is 'Sensible Pressure' at $\mathrm{A}$ would be after manipulation

$$
P_{s}=P-32 \mu\left[\frac{V l_{1}}{D_{1}^{2}}+\frac{V_{1} l_{2}}{D_{2}{ }^{2}}+\frac{V_{2} l_{3}}{D_{2}{ }^{2}}+\frac{c\left(l_{1}+l_{2}+l_{3}\right)}{\bar{D}^{2}}\right]-\frac{f_{s} \rho V_{1}^{2} \pi R_{b}}{2 D_{2}} \cdot \frac{\theta}{180^{\circ}}-\frac{K_{b} \rho V_{1}^{2}}{2}-\rho c \Delta V
$$

Where, $\mathrm{C}_{\mathrm{v}}, \mu \& \bar{D}$ and are Valve constant, dynamic viscosity and average diameter respectively. The other notations are defined earlier. The second term in the R.H.S. is the decay of pressure $\mathrm{P}_{\mathrm{s}}$ due to friction loss in pipe sensible at A. The following two terms are loss due to bending of pipe.

Through a computer monitor at $\mathrm{A}, \mathrm{P}_{\mathrm{s}}$ is sensed at $\mathrm{A}$ instead of $\mathrm{P}$. Thereby, we understand that Water Hammer occurs at $\left(C\right.$ at a distance $\left(1_{1}+l_{2}+l_{3}\right)$ from A. From (10), we estimate value of measureable Surge Pressure at A in SI unit with respect to $1_{1}, l_{2}, l_{3}$ with fixed diameter of pipe and material or value of total length of pipe for total Surge dissipation can be calculated with different pipe diameter for particular pipe material and different bend angle.

\section{Relationship between Surge Pressure and Lengths:}

To study the value of Surge Pressure and Length of pipe, the following physical parameters are used for Numerical analysis through Mat Lab. The sensible pressure at point A inside the pipe as shown in Fig. 2 is given by:

$$
P_{s}=P-32 \mu\left[\frac{V l_{1}}{D_{1}{ }^{2}}+\frac{V_{1} l_{2}}{D_{2}{ }^{2}}+\frac{V_{2} l_{3}}{D_{2}{ }^{2}}+\frac{c\left(l_{1}+l_{2}+l_{3}\right)}{\bar{D}^{2}}\right]-\frac{f_{s} \rho V_{1}^{2} \pi R_{b}}{2 D_{2}} \cdot \frac{\theta}{180^{\circ}}-\frac{K_{b} \rho V_{1}^{2}}{2}-\rho c \Delta V
$$

Where, 
Surge Pressure $=\mathrm{P}_{\mathrm{S}}$;

Angle of Bend, $\theta=90$;

Valve Constant, $\mathrm{C}_{\mathrm{V}}=0.85$;

Reynold's No, $\mathrm{R}_{\mathrm{e}}=2300$;

Moody friction factor $\mathrm{Re}=2300, \mathrm{f}_{\mathrm{s}}=0.3164 * \mathrm{Re}^{-0.25}$

Gravity, $g=9.81$;

Density, $\rho=10^{3}$;

Dynamic Viscosity, $\mu=1.004 * 10^{-3}$;

Moody Friction Factor for Reynold's no. 2300

$\mathrm{f}_{\mathrm{s}}=0.008$;

Radius of Bend, $\mathrm{R}_{\mathrm{b}}=2$;

Bend Loss coefficient, $K_{b}=0.285$;

Internal diameters:

$\mathrm{D} 1=0.75$

$\mathrm{D} 2=0.5$

Average diameter $=\mathrm{D}=(\mathrm{D} 1+\mathrm{D} 2) / 2$

Velocity at sensor position $\mathrm{A}, \mathrm{V}=2.8395$;

Velocity of water through branch line

$\Delta \mathrm{V}=\mathrm{V}_{2} * \mathrm{C}_{\mathrm{V}}$;

Celerity: steel $=1100$, Cast Iron $=850$, Concrete $=700, \mathrm{PVC}=300$

Initial pressure at $\mathrm{A}, \mathrm{P}=10^{*} 100^{2} ;\left(\right.$ in $\left.\mathrm{kg} / \mathrm{m}^{2}\right)$,

Now let us assume in equation (1),

$T_{1}=32 \mu ; T_{2}=\frac{V l_{1}}{D_{1}{ }^{2}} ; T_{3}=\frac{V_{1} l_{2}}{D_{2}{ }^{2}} ; T_{4}=\frac{V_{2} l_{3}}{D_{2}{ }^{2}} ; T_{5}=\frac{c\left(l_{1}+l_{2}+l_{3}\right)}{\bar{D}^{2}}$

$T_{6}=\frac{f_{s} \rho V_{1}^{2} \pi R_{b}}{2 D_{2}} \cdot \frac{\theta}{180^{\circ}} ; T_{7}=\frac{K_{b} \rho V_{1}^{2}}{2} ; T_{8}=\rho c \Delta V$

So, sensible pressure at $\mathrm{A}, \mathrm{P}_{\mathrm{S}}=P-T_{1}\left(T_{2}+T_{3}+T_{4}+T_{5}\right)-T_{6}-T_{7}-T_{8}$;

Now, if length is varied within permissible limits, then relational graphs of $\mathrm{P}_{\mathrm{S}} \mathrm{vs} .1_{1}, 1_{2} \& 1_{3}$ can be found (keeping the other parameters constant).

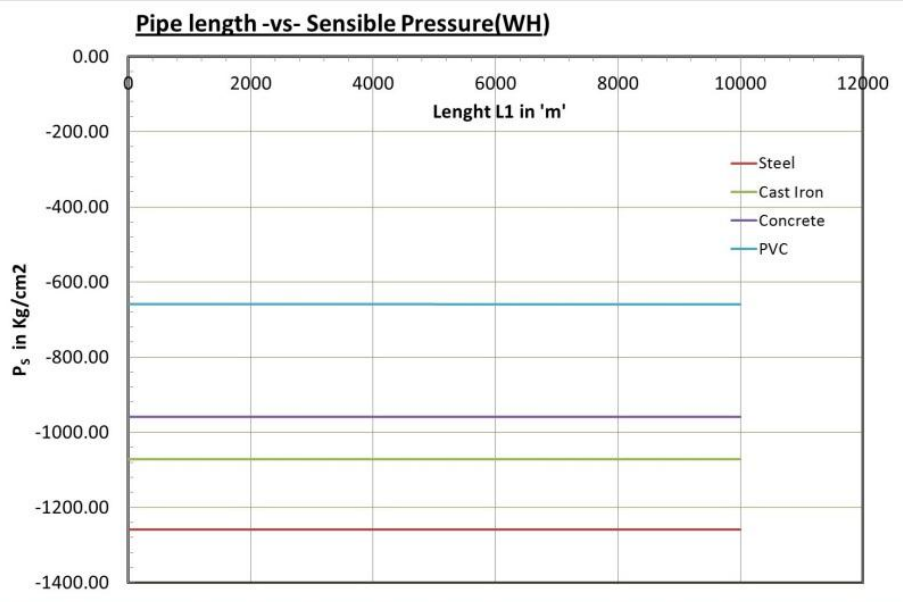

Fig.3: The relationship between sensible pressure of surge against Pipe length L1

It is observed for a closed distribution pipe segmental length does not absorb much energy of the water hammer pressure. Therefore if we place a pressure sensor a A in the pipe as shown in Fig.1 then it will sense hammer pressure significantly though the water hammer developed at very long distance. So with proper design of automation if pressure transmitter senses the surge pressure and it may give command to the control system to open some connected bypass line to release water hammer pressure and safe guard the pipe distribution system 


\section{Relationship between Lengths and Pipe IDs (under water hammer $P_{S}=0$ ):}

zero.

To find out the relationship between lengths and Pipe IDs, when surge pressure $P_{S}$ in equation (1) is

So, the equation becomes:

$$
\begin{aligned}
& P-32 \mu\left[\frac{V l_{1}}{D_{1}{ }^{2}}+\frac{V_{1} l_{2}}{D_{2}{ }^{2}}+\frac{V_{2} l_{3}}{D_{2}{ }^{2}}+\frac{c\left(l_{1}+l_{2}+l_{3}\right)}{\bar{D}^{2}}\right]-\frac{f_{s} \rho V_{1}^{2} \pi R_{b}}{2 D_{2}} \cdot \frac{\theta}{180^{\circ}}-\frac{K_{b} \rho V_{1}^{2}}{2}-\rho c \Delta V=0 \ldots \ldots \ldots \ldots . . .(b) \\
& \Rightarrow l_{1}=\frac{1}{32 \mu\left(\frac{V}{D_{1}{ }^{2}}+\frac{c}{\bar{D}^{2}}\right)}\left[P-\frac{32 \mu c\left(l_{2}+l_{3}\right)}{\bar{D}^{2}}-\frac{32 \mu V_{1} l_{2}}{D_{2}{ }^{2}}-\frac{32 \mu V_{2} l_{3}}{D_{2}{ }^{2}}-\frac{f_{s} \rho V_{1}^{2} \pi R_{b}}{2 D_{2}} \cdot \frac{\theta}{180^{\circ}}-\frac{K_{b} \rho V_{1}^{2}}{2}-\rho c \Delta V\right]
\end{aligned}
$$

Now, Let us assume in the above equation,

$T_{1}=\frac{32 \mu c\left(l_{2}+l_{3}\right)}{\bar{D}^{2}} ; T_{2}=\frac{32 \mu V_{1} l_{2}}{D_{2}{ }^{2}} ; T_{3}=\frac{32 \mu V_{2} l_{3}}{D_{2}{ }^{2}} ; T_{4}=\frac{f_{s} \rho V_{1}{ }^{2} \pi R_{b}}{2 D_{2}} \cdot \frac{\theta}{180^{\circ}}$

$T_{5}=\frac{K_{b} \rho V_{1}^{2}}{2} ; T_{6}=\rho c \Delta V ; X=32 \mu\left(\frac{V}{D_{1}^{2}}+\frac{c}{\bar{D}^{2}}\right)$

So, the equation in terms $1_{1}$ becomes: $l_{1}=\frac{1}{X}\left[P-T_{1}-T_{2}-T_{3}-T_{4}-T_{5}-T_{6}\right]$

Again from equation (2), we can get the expression for $l_{2}$ and $l_{3}$ respectively.

$l_{2}=\frac{1}{Y}\left[P-T_{1}-T_{2}+T_{3}-T_{4}-T_{5}-T_{6}\right]$

Where,

$T_{1}=\frac{32 \mu c\left(l_{1}+l_{3}\right)}{\bar{D}^{2}} ; T_{2}=\frac{32 \mu V l_{1}}{D_{1}{ }^{2}} ; T_{3}=\frac{32 \mu V_{2} l_{3}}{D_{2}{ }^{2}} ;$

$T_{4}=\frac{f_{s} \rho V_{1}^{2} \pi R_{b}}{2 D_{2}} \cdot \frac{\theta}{180^{\circ}}$

$T_{5}=\frac{K_{b} \rho V_{1}^{2}}{2} ; T_{6}=\rho c \Delta V ; Y=32 \mu\left(\frac{V_{1}}{D_{2}^{2}}+\frac{c}{\bar{D}^{2}}\right)$

$l_{3}=\frac{1}{Z}\left[P-T_{1}-T_{2}-T_{3}-T_{4}-T_{5}-T_{6}\right]$

Where,

$T_{1}=\frac{32 \mu c l_{1}}{\bar{D}^{2}}+\frac{32 \mu c l_{2}}{\bar{D}^{2}} ; T_{2}=\frac{32 \mu V l_{1}}{D_{1}^{2}} ;$

$T_{3}=\frac{32 \mu V_{1} l_{2}}{D_{2}^{2}} ; T_{4}=\frac{f_{s} \rho V_{1}^{2} \pi R_{b}}{2 D_{2}} \cdot \frac{\theta}{180^{\circ}}$

$T_{5}=\frac{K_{b} \rho V_{1}^{2}}{2} ; T_{6}=\rho c \Delta V$;

$Z=-32 \mu\left(\frac{V_{2}}{D_{2}^{2}}-\frac{c}{\bar{D}^{2}}\right)$ 
Now, if Pipe ID is varied within permissible limits, then relational graphs of $1_{1}, l_{2} \& 1_{3} V_{s} D_{1}$ and $D_{2}$ can be found (keeping the other parameters constant).

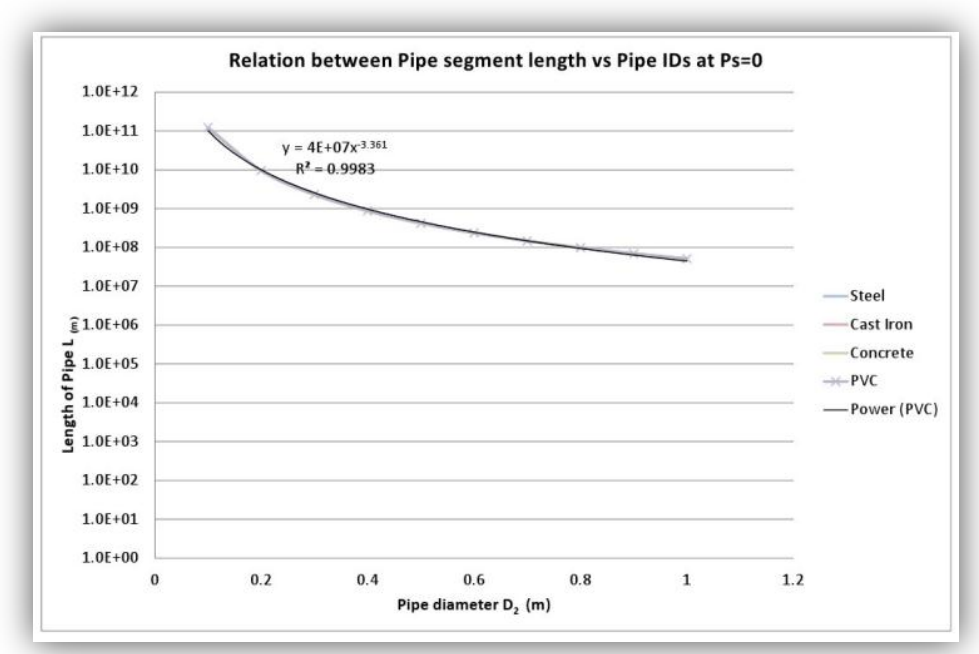

Fig.4: Relationship between pipe segments -vs- pipe ID with Ps is zero

The numerical analysis using standard pipe data and choosing pipe diameter variation from $0.15 \mathrm{~m}$ to $1 \mathrm{~m}$, a negative polynomial relationship between pipe diameters versus pipe length is observed with consideration of total absorption of surge pressure at point $\mathrm{A}$ of the piping system (Fig.1). The regression equation (Fig.4) shows very close relation between all materials of the pipe reveals celerity of the pipe material has no importance.

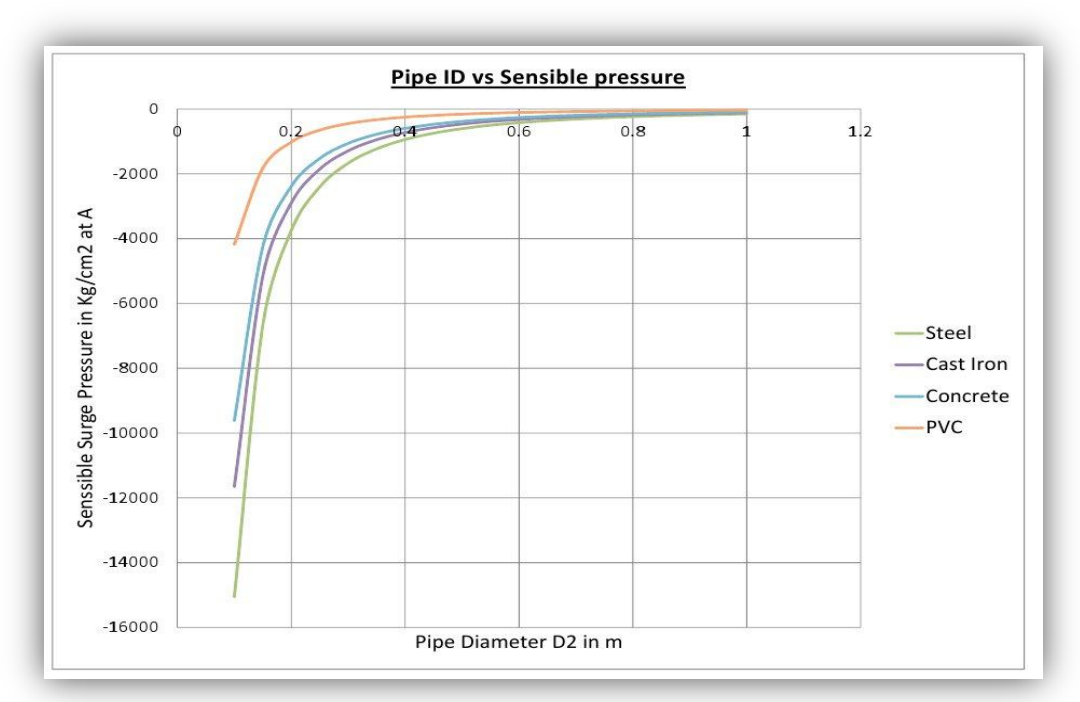

Fig.5: Relationship between sensible pressure and pipe diameter (ID) at particular bend angle and segmental length.

\section{Relationship between Angles (in degrees) and Surge Pressure:}

$$
P_{s}=P-32 \mu\left[\frac{V l_{1}}{D_{1}^{2}}+\frac{V_{1} l_{2}}{D_{2}^{2}}+\frac{V_{2} l_{3}}{D_{2}^{2}}+\frac{c\left(l_{1}+l_{2}+l_{3}\right)}{\bar{D}^{2}}\right]-\frac{f_{s} \rho V_{1}^{2} \pi R_{b}}{2 D_{2}} \cdot \frac{\theta}{180^{\circ}}-\frac{K_{b} \rho V_{1}^{2}}{2}-\rho c \Delta V
$$

In the above equation if $\theta$ is varied between 0 to $180^{\circ}$, then a graph between $\mathrm{P}_{\mathrm{S}}$ and $\theta$ can be obtained (keeping the other parameters constant). The numerical values for computation are same for the analysis made for other cases, $l_{1}, l_{2}$ and $l_{3}$ are kept same and considered $1000 \mathrm{~m}, \mathrm{D}_{1}$ is $0.75 \mathrm{~m}$ and $\mathrm{D}_{2}$ is $0.250 \mathrm{~m}$, the average diameter for calculation is considered $0.5 \mathrm{~m}$ 


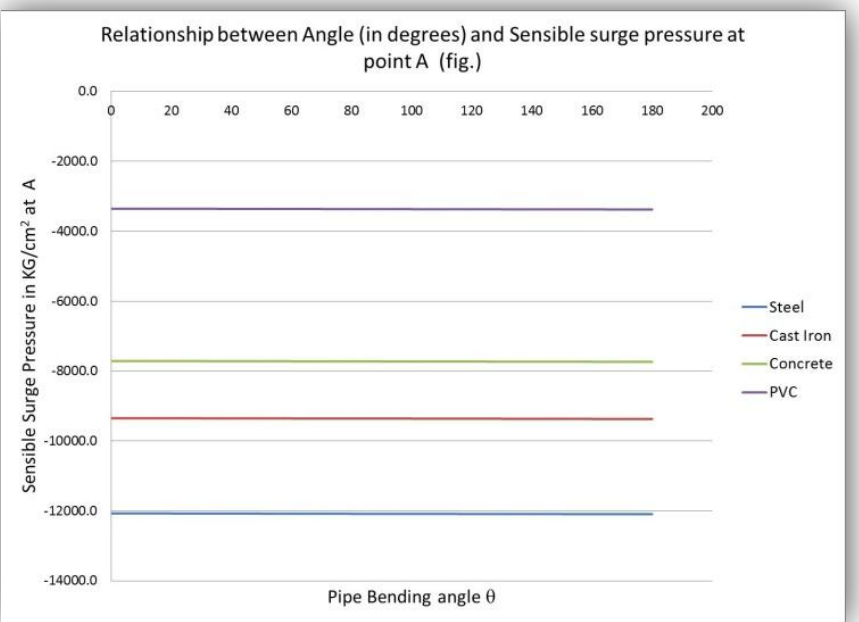

The remarkable observation is that the sensible pressure Ps at point of calculation due to surge pressure does not have any significant effect on change in pipe bending angle. But the values are sensitive to pipe material only.

\section{Relationship between Angles (in degrees) and Lengths:}

To find out relational graphs between pipe angle and lengths, surge pressure should be zero in the above equation. And then the individual expressions for $1_{1}, 1_{2}, 1_{3}$ can be found.

$$
\begin{aligned}
& P-32 \mu\left[\frac{V l_{1}}{D_{1}{ }^{2}}+\frac{V_{1} l_{2}}{D_{2}{ }^{2}}+\frac{V_{2} l_{3}}{D_{2}{ }^{2}}+\frac{c\left(l_{1}+l_{2}+l_{3}\right)}{\bar{D}^{2}}\right]-\frac{f_{s} \rho V_{1}^{2} \pi R_{b}}{2 D_{2}} \cdot \frac{\theta}{180^{\circ}}-\frac{K_{b} \rho V_{1}^{2}}{2}-\rho c \Delta V=0 \ldots \ldots \ldots \ldots \ldots . . .(d) \\
& \Rightarrow l_{1}=\frac{1}{32 \mu\left(\frac{V}{D_{1}{ }^{2}}+\frac{c}{\bar{D}^{2}}\right)}\left[P-\frac{32 \mu c\left(l_{2}+l_{3}\right)}{\bar{D}^{2}}-\frac{32 \mu V_{1} l_{2}}{D_{2}{ }^{2}}-\frac{32 \mu V_{2} l_{3}}{D_{2}{ }^{2}}-\frac{f_{s} \rho V_{1}^{2} \pi R_{b}}{2 D_{2}} \cdot \frac{\theta}{180^{\circ}}-\frac{K_{b} \rho V_{1}^{2}}{2}-\rho c \Delta V\right]
\end{aligned}
$$

Now, Let us assume in the above equation,

$$
\begin{aligned}
& T_{1}=\frac{32 \mu c\left(l_{2}+l_{3}\right)}{\bar{D}^{2}} ; T_{2}=\frac{32 \mu V_{1} l_{2}}{D_{2}^{2}} ; T_{3}=\frac{32 \mu V_{2} l_{3}}{D_{2}^{2}} ; T_{4}=\frac{f_{s} \rho V_{1}^{2} \pi R_{b}}{2 D_{2}} \cdot \frac{\theta}{180^{\circ}} \\
& T_{5}=\frac{K_{b} \rho V_{1}^{2}}{2} ; T_{6}=\rho c \Delta V ; X=32 \mu\left(\frac{V}{D_{1}^{2}}+\frac{c}{\bar{D}^{2}}\right)
\end{aligned}
$$

So, the equation in terms $1_{1}$ becomes: $l_{1}=\frac{1}{X}\left[P-T_{1}-T_{2}-T_{3}-T_{4}-T_{5}-T_{6}\right]$

Again from equation (d), we can get the expression for $l_{2}$ and $l_{3}$ respectively.

$l_{2}=\frac{1}{Y}\left[P-T_{1}-T_{2}+T_{3}-T_{4}-T_{5}-T_{6}\right]$

Where,

$$
\begin{aligned}
& T_{1}=\frac{32 \mu c\left(l_{1}+l_{3}\right)}{\bar{D}^{2}} ; T_{2}=\frac{32 \mu V l_{1}}{D_{1}{ }^{2}} ; T_{3}=\frac{32 \mu V_{2} l_{3}}{D_{2}{ }^{2}} ; T_{4}=\frac{f_{s} \rho V_{1}{ }^{2} \pi R_{b}}{2 D_{2}} \cdot \frac{\theta}{180^{\circ}} \\
& T_{5}=\frac{K_{b} \rho V_{1}^{2}}{2} ; T_{6}=\rho c \Delta V ; Y=32 \mu\left(\frac{V_{1}}{D_{2}{ }^{2}}+\frac{c}{\bar{D}^{2}}\right) \\
& \& l_{3}=\frac{1}{Z}\left[P-T_{1}-T_{2}-T_{3}-T_{4}-T_{5}-T_{6}\right]
\end{aligned}
$$


Where,

$$
\begin{aligned}
& T_{1}=\frac{32 \mu c l_{1}}{\bar{D}^{2}}+\frac{32 \mu c l_{2}}{\bar{D}^{2}} ; T_{2}=\frac{32 \mu V l_{1}}{D_{1}^{2}} ; T_{3}=\frac{32 \mu V_{1} l_{2}}{D_{2}{ }^{2}} \\
& T_{4}=\frac{f_{s} \rho V_{1}^{2} \pi R_{b}}{2 D_{2}} \cdot \frac{\theta}{180^{\circ}} ; T_{5}=\frac{K_{b} \rho V_{1}^{2}}{2} ; T_{6}=\rho c \Delta V ; Z=32 \mu\left(\frac{V_{2}}{D_{2}{ }^{2}}+\frac{c}{\bar{D}^{2}}\right)
\end{aligned}
$$

If we go on numerical analysis by putting the all design values of geometry of the pipe line and celerity values of different pipe materials then computed values of length of pipes will be negative, because the value of $\mathrm{T}_{6}$ is very high because of celerity. The bending angle will not contribute much in computation of pipe length.

Therefore:-

$$
\frac{1}{x}\left[P-T_{1}-T_{2}-T_{3}-T_{4}-T_{5}\right] \leq \frac{1}{x}\left[T_{6}\right]
$$

The effect of surge pressure is many times more on the system and surge travels in opposite direction. Therefore this part of study may be not significant for the present contest.

\section{CONCLUSION}

From numerical analysis it is found that sensible pressure due to water hammer is very significant and is detectable. Here one dimensional water hammer in pipe water distribution system is calculated only for pressure waves moving towards source but in physical case it is oscillatory in nature.

The one end of the distribution system is either connected to the pump or overhead reservoirs through branch lines and the final end is connected to storage tank at ground. So both the end of the distribution pipe may be considered as open end and the pressure wave developed due to water hammer die down shortly through these open end leakages. The collateral damage in piped system depends on the pipe material, thickness and weakness of the joint or surface of the pipe. The installation of surge tanks in certain interval throughout the water mains may be one solution to prevent damage in the pipe water distribution system otherwise an automatic pressure bypass system can be think off such as any excess pressure due to water hammer sensed by an electronic pressure sensor can open a bypass water pipe line to release the same instantaneously.

This analytical work on water hammer in piped water supply will help in designing the distribution pipe lines of various diameters and bends, but two dimensional analyses will be more predictive and is future scope of study.

\section{REFERENCES}

[1] M. S. Ghidaoui, M. Zaho, D. A. Mclnnisand D. H. Axworthy, A review of water hammer theory and practice, Transaction of the AMSE, 58, 2005, 49-75.

[2] A. K. Mitra and W. T. Rouleau, Radial and Axial variation in transient pressure waves transmitted through liquid transmission lines, AMSE J. Fluids Engg., 107, 1985, 105-111.

[3] A. E. Verdy and K. L. Hwang, A Characteristic model of transient friction in pipes, J. Hydraul. Res., 29(5), 1991, 669-685.

[4] A. S. Tijsseling, Fluid structure interaction in liquid-filled pipe systems: A review, J. Fluid Struct., 10, 1995, $109-146$.

[5] G. Pezzinga, Quasi-2D model for unsteady flow in pipe networks, J. Hydraul. Eng., 123(2), 1999, 108-115.

[6] A. Bergant, A. R. Simpson and J. Vitkovsky, Development in unsteady pipe flow friction modeling, J. Hydraul. Res., 39, 2001, 249-257.

[7] Rowe, M. (1970) Measurement and computation of flow in pipe bends, J. Fluid Mech., 43:771-783. DOI: 10.1017/S0022112070002732

[8] Arris, S. Tijsseling and A. Alexander, The Joukowsky equation for fluids and solids (http://www.win.tue.n1/analysis/reports/rana06-08.pdf )

[9] R. K. Bansal, Fluid Mechanics and Hydraulic Machines (Laxmi Publishers (P) Ltd., 2000)

[10] A. H. Gibson, Water hammer in hydraulic pipelines(Archibald Constable, London, UK, 1908)

[11] A. K. Jain, Fluid Mechanics (Khanna Publishers, New Delhi, 1996)

[12] Idelchik, I. E. Handbook of Hydraulic Resistance (Hemisphere Publishing Corp., Washington, 1986)

[13] A. J. Tijsseling and A. Anderson, The joukowsky equation for fluids and solids, CASA Reports, Dept. of Mathematics and Computer Science, EindohovenUniversityof Technology, March, 2006.

[14] R. Misra, Automation-The key to water management, Indepth- Instrumentation \& Process Control, Everything about water, Forbes Marshall February 2008, 26-31.

[15] J. P. Frizell, Pressures resulting from changes of velocity of water in pipes, Transactions of the ASCE 39, Paper 819, 1-18.

[16] V. L. Streeter and C. Lai, Water hammer analysis including friction, Tran, Am. Soc. Civ. Eng. 128, 1491-1524.

[17] J. K. Roy, P. K. Roy and P. Basak, Water Hammer protection in water supply system- a new approach with practical implementation, IEEE International Conference on Communication and Industrial Application, Kolkata, (ICCIA2011)Dec 26-28, 2011, IEEE DigitalXploreDOI: 10.1109/ICCIndA.2011.6146652

[18] Anton Bergant and ArrisTijsseling, Parameters Affecting Water Hammer Wave Attenuation, Shape and Timing, Rana Reports, Centre for Analysis, Scientific Computing and Applications, Dept. of Computer Science, Eindhoven University of Technologya.s.tijsseling@TUE.nl 